\title{
Can Warm Behavior Mitigate the Negative Effect of Unfavorable Governmental Decisions on Citizens' Trust?
}

\author{
Frederik Godt Hansen (D) \\ Department of Political Science, Aarhus University, Bartholins Allé 7, Aarhus C, 8000, Denmark. Twitter: \\ @FrederikGodt \\ Email: frederik@ps.au.dk
}

\begin{abstract}
For decades, scholars have discussed how to build greater citizen trust in government. I hypothesize that to increase trust in government, we should consider whether decisions made in bureaucrat-citizen encounters (e.g. applications for welfare benefits) are favorable to citizens. Building on insights from social psychology, I argue that in cases where citizens are presented with unfavorable decisions (e.g. rejection of applications), public employees can mitigate the negative impact on trust in government by appearing warm and friendly in the decision-making process. The argument is tested in a large-scale randomized survey experiment on a representative sample of Danish citizens, where I manipulate decision favorability and warmth. The findings reveal that outcome favorability and warmth strongly influence citizens' trust in government.
\end{abstract}

Keywords: Warmth; survey experiment; trust in government; political trust; citizen-state encounter

\section{Introduction}

Citizens' trust in government is fundamental to democratic legitimacy and the effectiveness of government policies and services (Dalton 2004; OECD 2017; Citrin and Stoker 2018). Trust, for instance, provides public organizations and employees with legitimate bureaucratic discretion and power to make decisions (Carpenter 2001; Cooper, Knotts, and Brennan 2008; Lee and Van Ryzin 2020) and encourage citizen compliance with government regulations (Scholz and Lubell 1998; Marien and Hooghe 2011).

Political scientists have consistently emphasized that citizens base their trust and support in political institutions on whether those institutions provide them with societal outcomes (e.g. a healthy economy) and decisions that fit policy preferences (Popkin 1991; Nannestad and Paldam 1994; Keele 2007; Pop-Eleches and Pop-Eleches 2012; Van Erkel and Van der Meer 2016). Government institutions,

\footnotetext{
(1) This article has earned badges for transparent research practices: Open Data and Open Materials. For details see the Data Availability Statement.

(C) The Author(s) 2021. Published by Cambridge University Press on behalf of The Experimental Research Section of the American Political Science Association
} 
however, also make decisions based on interactions where citizens apply for services such as welfare benefits or healthcare. Even though street-level bureaucrats have legitimate discretion to make many significant decisions with direct implications for an individual's welfare (Lipsky 1980; Maynard-Moody and Musheno 2003), much less is known about the relationship between these decisions and citizens' trust. I examine to what extent decisions provided in bureaucrat-citizen encounters influence citizens' trust in government.

Decisions can be favorable or unfavorable and research has emphasized that decision favorability is important for improving citizens' trust (e.g. Allen and Birch 2015). However, we might not fully understand how citizens make sense of bureaucratic encounters if we only consider whether decisions are favorable to the individual (Hibbing and Alford 2004). Social psychology teaches us that upon encountering others, people spontaneously form impressions of how the other performs on warmth-related traits and this impression predicts evaluative judgments (Wojciszke, Bazinska, and Jaworski 1998; Judd et al. 2005; Fiske, Cuddy, and Glick 2007; Cuddy, Fiske, and Glick 2007). Warmth is widely acknowledged as the main dimension along which people evaluate each other, and it encompasses traits such as friendliness, kindness, and likability (Fiske, Cuddy, and Glick 2007; Laustsen and Bor 2017; Pedersen 2017). I expect citizens to react with lower trust when receiving negative decisions because their interests are not fulfilled. Warmth, however, gives some counterweight to the negative decision, which can make citizens less inclined to lower their trust when decisions are unfavorable. I test this argument in a $2 \times 2$ survey experiment fielded to a representative sample of Danish citizens $(\mathrm{N}=1,613)$ in which I manipulate the favorability of decisions and how public employees act according to warmth-related traits.

This study applies broadly to bureaucratic behavior since citizen-state interactions are a key part of delivering core public services across countries. The survey experimental findings show that citizens respond with higher levels of trust in government when bureaucrats deliver favorable decisions to the individual and when bureaucrats behave in a warm way. However, warmth appears not to reduce citizens' negative reactions to unfavorable outcomes.

\section{Decision favorability, warmth impressions, and citizens' trust}

At its core, trust in government relates to whether citizens have positive perceptions of the government's ability, benevolence, and integrity (Grimmelikhuijsen and Meijer 2014; Mayer, Davis, and Schoorman 1995). For decades, studies have established that politicians and political institutions earn citizens' trust by generating favorable outcomes. Most prominently, positive perceptions of macroeconomic outcomes lead to greater trust in and support for government (Citrin and Green 1986; Nannestad and Paldam 1994; Hetherington 1998; Chanley, Rudolph, and Rahn 2000; Lewis-Beck and Stegmaier 2013; Van Erkel and Van der Meer 2016). Hence, demonstrating results and producing outcomes "that matter to citizens" is seen as key to securing citizens' trust in government (Van Ryzin 2011, 746). Public employees daily make decisions of significant importance to individuals when interacting with citizens in the delivery of public services (Lipsky 1980). 
In these situations, I argue that citizens' trust depends on whether decisions made by bureaucrats are favorable.

Psychologically, people can approach new information, such as decisions made by bureaucrats, in different ways. Sometimes, individuals search for accurate information to draw correct conclusions, and sometimes individuals engage in making judgments that fit pre-defined conclusions (Kunda 1990; Kruglanski and Webster 1996). Regarding the latter, recurring studies have revealed that people, in general, tend to evaluate new evidence in a way that reflects a myside bias (Perkins 1985; Wolfe, Britt, and Butler 2009; Stanovich, West, and Toplak 2013). That is, when no cues to avoid doing so are given, people will tend to "evaluate propositions from within one's own perspective" (Stanovich and West 2007, 225). Furthermore, since bureaucrats' decisions have significant meaning for the individual, I expect citizens to be even more inclined to defend their prior beliefs, positions, and interests. The longer-term result of defending their pre-defined position is to react with higher or lower trust in government depending on whether the decision is favorable to the individual. Thus, citizens will make trust judgments in a biased manner such that receiving a favorable decision yields greater trust in government compared to receiving an unfavorable decision.

H1: Citizens have lower trust in government the more unfavorable a decision is to the individual.

Yet citizens might be willing to overlook unfavorable decisions if they have positive perceptions of encounters with bureaucrats on other dimensions; such as how decisions come about (Hibbing and Theiss-Morse 2002; Grimes 2006; Bøggild and Petersen 2016). A well-established finding in social and organizational psychology is that procedural fairness can reduce the negative impact of unfavorable outcomes on support for authorities (Tyler 1990; Brockner and Wiesenfeld 1996; Colquitt et al. 2001; Brockner 2011). Informed by this psychological research, political scientists have recently begun to investigate this interaction in a political context (Bøggild 2016; Esaiasson et al. 2019; Magalhaes and Aguiar-Conraria 2019). These studies focus strictly on principles of fairness related to the process such as voice or impartiality.

However, when we talk about concrete interactions between citizens and public employees, people might also be interested in other aspects than fairness. Scholars in social psychology consistently argue that impressions of the other's warmth ${ }^{1}$ (e.g. friendliness or likability), is fundamental to impression formation in such encounters (Wojciszke, Bazinska, and Jaworski 1998; Fiske et al. 2002; Fiske, Cuddy, and Glick 2007; Abele et al. 2008). While warmth is not theoretically orthogonal to procedural fairness (for instance, both dimensions refer to honesty), the warmth perspective might add new knowledge about what citizens find important in encounters with public employees. Importantly, the broad warmth dimension encompasses separable and distinct sub-components (Leach, Ellemers, and Barreto 2007; Brambilla et al. 2012). In particular, scholars argue and find

\footnotetext{
${ }^{1}$ Some scholars refer to the warmth dimension by the label "communion" (e.g. Abele and Wojciszke 2007; Fiske 2018; Abele and Hauke 2020). However, the conceptual meaning is similar (Abele et al. 2008).
} 
experimental evidence of that a conceptually distinct part of the broader warmth dimension consists of "pure" warmth traits which are related to sociability and forming connections with others (Goodwin, Piazza, and Rozin 2014). ${ }^{2}$ For instance, Brambilla et al. (2011) define this aspect by referring to five traits: kind, friendly, warm, likable, and helpful. These traits are clearly distinct from fairness criteria. We would overlook these pure warmth-related traits if we only examined the interactions with a narrow procedural fairness lens. This article contributes by asking whether this core aspect of the general warmth dimension interacts with outcome favorability.

Social psychology argues that warmth impressions build on evolutionary pressures where the other's warmth is more important for survival than the other's abilities (Fiske, Cuddy, and Glick 2007). Thus, we can expect that warmth impressions carry weight when citizens form trust evaluations based on bureaucrats' decisions. This idea of warmth being a driver of trust also aligns well with the argument that we judge the trustworthiness of other individuals by evaluating their benevolence (Mayer, Davis, and Schoorman 1995).

The question then becomes how warmth impressions shape citizens' trust when we also consider the favorability of decisions. How do people update their trust in government when they encounter an unfavorable decision delivered by a warm bureaucrat? I argue that street-level bureaucrats can mitigate citizens' negative responses to unfavorable decisions by genuinely emphasizing warmth in the decision-making process. Citizens receive not only negative information in terms of an adverse decision, but also positive information concerning warmth. Individuals need cues to avoid evaluating negative decisions according to a myside bias (Stanovich and West 2007), and people are generally only motivated to arrive at a particular, pre-defined conclusion "if they can muster up the evidence necessary to support it" (Kunda 1990, 483). I contend that warmth function as a cue of positive information, which could somewhat counterweigh the negative information from the unfavorable decision, even though warmth does not change the factual basis of the decision. Evidence suggests that information incongruent with expectations can reduce the motivation to engage in biased evaluations (see, e.g. Redlawsk, Civettini, and Emmerson 2010).

In the case of citizens' interactions with government, the theoretical mechanism connecting warmth and trust might be that citizens infer perceptions of the bureaucrat's competence or procedural fairness when receiving cues about warmth (a halo effect). That is, when you encounter a warm and friendly bureaucrat, you might use this as a cue for that the process generally has been fair, which we know increases citizens' trust and decision acceptance (e.g. Tyler 1990; Hibbing and Alford 2004; Bøggild 2016). Another theoretical mechanism might be that cues about warmth work through perceived competence (Fiske, Cuddy, and Glick 2007, 79).

When individuals benefit from the decision it is less clear whether warmth impacts citizen trust. On the one hand, individuals genuinely care about warmth and should, thus, improve citizens' experience of the interaction and their trust. However, following an argument from the procedural fairness literature, people

\footnotetext{
${ }^{2}$ The Sub-Dimension of "pure warmth" is also referred to as "sociability" which is distinct from a moral aspect of the general warmth dimension (see, e.g. Brambilla et al. 2011.)
} 
might tend to overlook other dimensions of the social context, such as warmth, when they are at the receiving end of decisions (Brockner and Wiesenfeld 1996; Esaiasson et al. 2019).

H2: The effect of decision favorability on citizens' trust in government depends on whether bureaucrats show warmth in the decision-making process. The negative effect of unfavorable decisions is weaker when bureaucrats show high warmth compared to showing low warmth.

\section{Experimental design}

The study is based on a $2 \times 2$ factorial survey experiment ${ }^{3}$ among 1,613 Danish citizens recruited through YouGov's web panel from 25 February to 6 March 2021. The sample is representative of the Danish population on age, gender, education, and residence (see the Appendix for a power analysis and sample characteristics).

\section{Case: elderly care in Denmark}

To examine the hypotheses, I need a case that meets three main criteria. First, to enhance experimental realism, the case has to concern a salient service area to which most people can relate. Second, I need a case where bureaucrats have the discretion to make important decisions for citizens. Third, the case requires a bureaucrat-citizen interaction for citizens to evaluate the bureaucrat on warmth-related traits. Danish public nursing homes provide a suitable case for this purpose. In a Danish setting, most respondents can relate emotionally to elderly care, since it is a core part of the Danish universal welfare system (85\% of Danish nursing homes are public organizations) (Thomsen and Jensen 2020). In Denmark, there are about 80,000 housing units for senior citizens, and around 150,000 elderly citizens receive assistance in their own homes (out of about a million citizens above the age of 65). ${ }^{4}$ Thus, in a Scandinavian context, "most adults have relatives or friends who use such services and will eventually need such services" (Berg and Johansson 2020,6). Furthermore, elderly care and shortage of senior housing (Berlingske 2019) are highly prioritized on citizens' agenda. For instance, according to data from the Danish National Election Study 2019, more than 70\% of citizens responded that elderly care had some or a big influence on their vote choice in the 2019 general election and $65 \%$ believe that unsatisfactory conditions in elderly care is a big problem. ${ }^{5}$

Furthermore, decisions about who is entitled to a place in a nursing home in Denmark require bureaucratic discretion. This decision, which is provided by the municipalities, involves an individual judgment since no fixed eligibility criteria or decision rules exist (Ministry of Health 2017). The elderly citizen interacts with a

\footnotetext{
${ }^{3}$ Pre-registered at OSF: https://osf.io/4b85p/?view_only=d17085e07c4446c58e91f11e293b5104.

${ }^{4}$ Data from Statistics Denmark (2020a, 2020b).

${ }^{5}$ See www.surveybanken.aau.dk.
} 
bureaucrat from the municipality who evaluates the citizen's general health situation and specific needs. The citizen can bring a companion or relative to the meeting. Based on a recommendation from the bureaucrat, the municipality decides whether to approve the application and offer the elderly citizen care at a nursing home. Given that the municipality is responsible for these decisions, I focus on trust in the local government.

\section{Experimental stimuli}

In the experiment, participants were instructed to read a brief vignette on the issue of approval to Danish nursing homes. To improve mundane realism, the vignette closely depicts how people interact with public employees regarding elderly care in the real world. Thus, I asked each respondent to imagine helping a close relative with the application for a place in a nursing home and being involved in the interaction with a bureaucrat from the municipality, who has to clarify the need for care (see Appendix A).

As I experimentally manipulated decision favorability and the bureaucrat's warmth, respondents were randomly assigned to one of the four treatment groups. Other studies have successfully manipulated warmth by providing respondents with a written vignette (e.g. Laustsen and Bor 2017), as the survey experimental design allows us to make strong causal claims. However, asking people to imagine being granted or denied access to social benefits should yield a smaller reaction compared to a realworld bureaucratic encounter. Thus, we should expect to obtain conservative estimates.

Warmth was manipulated with reference to whether the caseworker is friendly, kind, likable, good-natured, and warm. These features are well-established traits characterizing warmth across a variety of settings (Fiske et al. 1999; Fiske et al. 2002; Halkias and Diamantopoulos 2020), and more importantly capture the "pure" part of the broad warmth dimension (Brambilla et al. 2011; Brambilla et al. 2012; Goodwin, Piazza, and Rozin 2014; Abele and Hauke 2020). To increase realism and measurement validity (see Fiske et al. 1999), the two conditions depicting the bureaucrat as low in warmth use not only negative items (e.g. unfriendliness), but also cues about low performance on a positive trait (e.g. "the caseworker does not seem very likable and good-natured."). While other experimental studies manipulate criteria of fairness (Hibbing and Alford 2004), the manipulations in this vignette enable me to examine whether cues that only concern "pure" warmth in fact influence trust through perceptions of procedural fairness (or perceptions of competence).

Along with manipulations of warmth, I provided participants with information about decision favorability by stating whether the application to enter a nursing home was rejected (unfavorable condition) or approved (favorable condition) by the municipality. The vignette clearly indicates that the care recipient (the participant's close relative) needs a place in a nursing home.

\section{Measures}

To measure citizens' trust, this study poses a question about citizens' trust in the local government (municipalities in a Danish context) and a question about citizens' trust in the caseworker. Both items are measured on $0-10$ scales, but recoded to 
0-1 scales (higher values indicating higher trust). Particularly, participants responded to "How much do you personally trust the municipality/the caseworker to make the right decisions?"

To explore the theoretical mechanism, respondents indicated how they perceived the caseworker from the vignette on traits related to the overall dimensions of pure warmth, competence, and procedural fairness. The decision favorability manipulation was assessed on a 7 -point scale ( 1 = "Very unfavorable"; $7=$ "Very favorable"), and participants' attention to the experimental material was examined by asking them to indicate with which service area the vignette was concerned. ${ }^{6}$ Finally, participants answered demographic questions about their gender, age, political ideology, education, attitudes toward public service provision, and whether they have close relatives living in a nursing home (users of elderly care). The two experimental manipulations were coded into two dummy variables. The full question wordings can be found in Appendix A.

\section{Results}

First, as expected based on the design of the treatment material, the rejection was perceived as significantly less favorable than the approval $\left(\mathrm{M}_{\text {Low OF }}=.23, \mathrm{M}_{\mathrm{HighOF}}=\right.$ $.67, p<.001)$ and respondents rated the caseworker significantly more warm in the high warmth condition compared to the low warmth condition $\left(\mathrm{M}_{\text {Lowwarmth }}=.19\right.$, $\mathrm{M}_{\text {Highwarmth }}=.7, p<.001$ ).

Models 1 and 2 in Table 1 present the results from ordinary least squares regressions (OLS) of the two trust outcomes on dummy variables for the outcome favorability treatment and warmth treatment. The first theoretical expectation ( $\mathrm{H} 1)$ predicted that the favorability of decisions has a direct positive effect on citizens' trust in government. The findings suggest that the outcome favorability manipulation significantly increases trust in the bureaucrat with $18.8 \%$ points $(p<.001)$. Moreover, in line with $\mathrm{H1}$, it appears from model 2 that the municipality receives significantly higher levels of trust when delivering a favorable decision to citizens relative to delivering an unfavorable decision $(17.9 \%$ points; $p<.001)$. In terms of substantial significance, the coefficients for outcome favorability correspond to large effect sizes of .76-.78 standard deviations on the dependent variables. Even though no formal hypothesis was formulated, it follows from the theory that the warmth manipulation also should have a direct effect on citizens' trust in government. Models 1 and 2 exploratively reports significant effects $(p<.001)$ of the bureaucrat's warmth on trust in the bureaucrat $(9.1 \%$ points) and trust in the municipality (4.7\% points). The effects are smaller with Cohen's $d$ of .36 for trust in the bureaucrat and .19 for trust in the municipality.

$\mathrm{H} 2$ predicted that the effect of outcome favorability would be weaker when bureaucrats show high warmth compared to low warmth. To find support for this expectation, we should observe that the mean difference in trust between unfavorable and favorable outcomes is significantly different in cases of high warmth compared to cases of low warmth. However, the insignificant interactions terms between

\footnotetext{
${ }^{6}$ Eighty eight percent of respondents correctly identified the service area of the scenario. The main results are not altered when excluding these respondents (results are not shown).
} 
Table 1

Experimental Results

\begin{tabular}{|c|c|c|c|c|}
\hline & $\begin{array}{c}\text { Trust } \\
\text { bureaucrat }\end{array}$ & $\begin{array}{c}\text { Trust } \\
\text { municipality }\end{array}$ & $\begin{array}{c}\text { Trust } \\
\text { bureaucrat }\end{array}$ & $\begin{array}{c}\text { Trust } \\
\text { municipality }\end{array}$ \\
\hline & (1) & (2) & (3) & (4) \\
\hline \multirow{2}{*}{$\begin{array}{l}\text { Outcome favorability } \\
\text { (OF) }\end{array}$} & ${ }^{\star * \star} 0.188$ & $\star \star * 0.179$ & ${ }^{\star * \star} 0.171$ & $* \star * 0.171$ \\
\hline & $(0.012)$ & $(0.012)$ & $(0.017)$ & $(0.017)$ \\
\hline \multirow[t]{2}{*}{ Warmth } & ${ }^{\star * \star} 0.091$ & ${ }^{* * *} 0.047$ & ${ }^{* * *} 0.073$ & ${ }^{*} 0.039$ \\
\hline & $(0.012)$ & $(0.012)$ & $(0.017)$ & $(0.017)$ \\
\hline \multirow[t]{2}{*}{$\mathrm{OF}^{*}$ Warmth } & & & 0.035 & 0.016 \\
\hline & & & $(0.024)$ & $(0.024)$ \\
\hline \multirow[t]{2}{*}{ Constant } & ${ }^{* \star *} 0.329$ & ${ }^{\star \star *} 0.355$ & ${ }^{* * *} 0.338$ & ${ }^{* \star *} 0.359$ \\
\hline & $(0.011)$ & $(0.010)$ & $(0.012)$ & $(0.012)$ \\
\hline Observations & 1,516 & 1,525 & 1,516 & 1,525 \\
\hline Adjusted $R^{2}$ & 0.162 & 0.135 & 0.163 & 0.135 \\
\hline
\end{tabular}

NOTES: OLS regressions. Standard errors are represented in parentheses in models 1 and 2. Heteroscedastic robust standard errors are used in models 3 and 4.

${ }^{\star} p<0.05 ;{ }^{\star *} p<0.01 ;{ }^{\star * *} p<0.001$.

the two treatments in models 3 and 4 show that warmth does not reduce the overall effect of outcome favorability. This implies that citizens, contrary to the expectation (H2), respond strongly to unfavorable outcomes with lower levels of trust even in cases of warm behavior by bureaucrats.

Comparing the gray bars in Figure 1 demonstrates that in cases of receiving unfavorable decisions, higher warmth significantly increases both trust outcomes $(p<.05$; see also the coefficients for "warmth" in models 3 and 4$)$. Yet, the figure further shows that the reason behind the insignificant interaction terms is that warmth also increases the effect on trust in cases of favorable outcomes (comparing the black bars; $p<.001$ ). This underlines that warmth still is important since warm behavior by bureaucrats influence citizens' trust judgments independently of outcome favorability. ${ }^{7}$

\section{Discussion and conclusion}

This experimental study sought to contribute to our understanding of what drives citizens' trust in government (e.g. Citrin and Stoker 2018; Van Ryzin 2011); more specifically the impact of bureaucratic behavior and performance in citizen-state

\footnotetext{
${ }^{7}$ A causal mediation analysis (Imai, Tingley, and Keele 2010; Imai et al. 2011; Tingley et al. 2014) performed in Appendix $\mathrm{F}$ suggest that perceived fairness and competence might be potential mediators connecting warmth to citizens' trust. Furthermore, it was explored whether treatment effects were stronger among participants who have a relative in a nursing home. Overall results suggest a slightly stronger reaction to the warmth treatment among users (see Appendix E).
} 

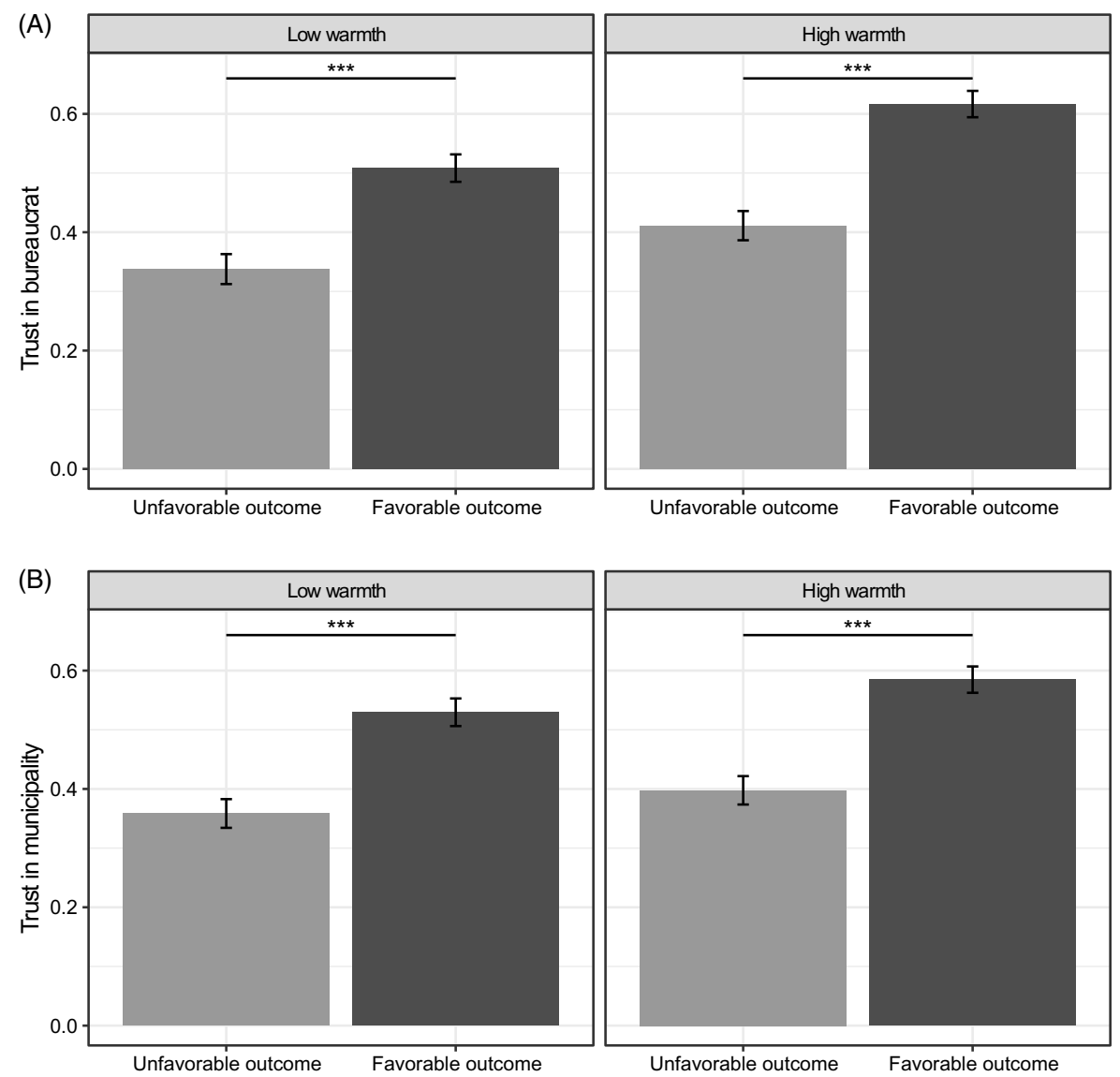

Figure 1

Interaction Estimates.

Notes: Effect of the outcome favorability manipulation on trust in the bureaucrat (panel A) and trust in the municipality (panel B) conditional on the warmth treatment. Bars are means and lines are $95 \% \mathrm{Cls} .{ }^{\star \star \star} p<0.001$.

interactions. In particular, it was examined through a large-scaled survey experiment whether warm behavior by bureaucrats in interactions with citizens could mitigate the negative effect of providing citizens with unfavourable outcomes on citizens' trust in government.

In line with earlier work (e.g. Popkin 1991; Allen and Birch 2015), the main results show that, also in bureaucrat-citizen interactions, citizens respond with higher levels of trust in government when bureaucrats provide them with favorable outcomes. In addition to outcomes, the results suggest that citizens are influenced by the bureaucrat's warmth traits and respond with higher levels of trust when the bureaucrat is perceived as acting in a warm manner. It is important to note that the findings imply wider-ranging effects of both warmth and outcomes since both aspects have independent effects on not only trust in the bureaucrat but further 
on trust in the municipality more generally. Even though the effect sizes are smaller for warmth, the estimates might be lower bounds. That is, the identified effects should be larger in the real-world where people are expected to react stronger to the treatments since real outcomes are at stake. Yet, even small changes in trust can have substantial implications for smooth and successful citizen-state interactions.

While the findings back up the conclusions from earlier studies about that citizens genuinely care about (pure) warmth (Wojciszke, Bazinska, and Jaworski 1998; Fiske, Cuddy, and Glick 2007; Brambilla et al. 2011; Fiske 2018), the findings do not support the theoretical expectation that warm bureaucratic behavior reduces the effect of outcome favorability on citizens' trust in either the bureaucrat or the municipality. However, the results (see Appendix F for details) indicate that the effect of warmth on citizens' trust might potentially be mediated by perceived fairness. Thus, the lack of an interaction effect speaks to the literature about whether outcome favorability and procedural fairness interact in predicting citizens' reactions (Brockner and Wiesenfeld 1996; Bøggild 2016; Esaiasson et al. 2019). On the one hand, the findings presented here are in line with Bøggild (2016) who finds no interaction between outcome favorability and procedural fairness. However, it is also possible that warmth did not affect procedural fairness enough to offset the negative effect of unfavorable outcomes. Given that the estimates of warmth are conservative, we might find the expected interaction effect in a real-world situation. Yet, this is a question for future research, and such studies could also include experimental manipulations of both warmth and procedural fairness.

This study is limited by the low external validity of the survey experimental setting, but as stated earlier the estimates are likely to be larger in a real-world situation compared to the experiment. Still, future studies may want to examine whether the findings generalize across service areas of the public sector and to countries where the public sector plays a lesser role in providing services to citizens.

Concluding, the direct effects of warmth imply that public leaders should be concerned about whether their employees behave in a warm manner if they want to build greater trust. Either by motivating them to show warmth when interacting with citizens or by taking warmth into consideration when recruiting new bureaucrats.

Supplementary Material. To view supplementary material for this article, please visit https://doi.org/10. 1017/XPS.2021.23.

Data Availability Statement. Support for this research was provided by the Department of Political Science, Aarhus University. The data, code, and any additional materials required to replicate all analyses in this article are available at the Journal of Experimental Political Science Dataverse within the Harvard Dataverse Network (Hansen 2021), at: https://doi.org/10.7910/DVN/KAMSQK

Acknowledgments. I thank Lasse Laustsen, Martin Bækgaard, Lene Aarøe, the editor, and the anonymous reviewers for helpful comments on previous drafts of this article.

Funding. This research was supported by funding from the Department of Political Science, Aarhus University.

Conflicts of Interest. The author declares no conflicts of interest. 


\section{References}

Abele, Andrea E., Amy J. C. Cuddy, Charles M. Judd, and Vincent Y. Yzerbyt. 2008. Fundamental Dimensions of Social Judgment. European Journal of Social Psychology 38 (7): 1063-1065. https://doi. org/10.1002/ejsp.574.

Abele, Andrea E., and Nicole Hauke. 2020. Comparing the Facets of the Big Two in Global Evaluation of Self versus Other People. European Journal of Social Psychology 50 (5): 969-982. https://doi.org/10.1002/ ejsp.2639.

Abele, Andrea E., and Bogdan Wojciszke. 2007. Agency and Communion from the Perspective of Self versus Others. Journal of Personality and Social Psychology 93 (5): 751-763. https://doi.org/10.1037/ 0022-3514.93.5.751.

Allen, Nicholas, and Sarah Birch. 2015. Process Preferences and British Public Opinion: Citizens' Judgements about Government in an Era of Anti-Politics. Political Studies 63 (2): 390-411. https:// doi.org/10.1111/1467-9248.12110.

Berg, Monika, and Tobias Johansson. 2020. Building Institutional Trust Through Service Experiences| Private Versus Public Provision Matter. Journal of Public Administration Research and Theory 30 (2): 290-306. https//doi.org/10.1093/jopart/muz029.

Berlingske. 2019. DI: Der kommer til at mangle 35.000 plejehjemspladser i 2030 [in da]. https://www. berlingske.dk/content/item/1336777.

Bøggild, Troels. 2016. How Politicians' Reelection Efforts Can Reduce Public Trust, Electoral Support, and Policy Approval. Political Psychology 37 (6): 901-919. https://doi.org/10.1111/pops.12303.

Bøggild, Troels, and Michael Bang Petersen. 2016. The Evolved Functions of Procedural Fairness: An Adaptation for Politics [in en]. In The Evolution of Morality, edited by Todd K. Shackelford and Ranald D. Hansen, 247-276. New York: Springer. https://doi.org/10.1007/978-3-319-19671-812.

Brambilla, Marco, Patrice Rusconi, Simona Sacchi, and Paolo Cherubini. 2011. Looking for Honesty: The Primary Role of Morality (vs. Sociability and Competence) in Information Gathering [in en]. European Journal of Social Psychology 41 (2): 135-143. https://doi.org/10.1002/ejsp.744.

Brambilla, Marco, Simona Sacchi, Patrice Rusconi, Paolo Cherubini, and Vincent Y. Yzerbyt. 2012. You Want to Give a Good Impression? Be Honest! Moral Traits Dominate Group Impression Formation [in eng]. British Journal of Social Psychology 51 (1): 149-166. https://doi.org/10.1111/j.20448309.2010.02011.x.

Brockner, Joel. 2011. A Contemporary Look at Organizational Justice: Multiplying Insult Times Injury. New York: Routledge.

Brockner, Joel, and Batia M. Wiesenfeld. 1996. An Integrative Framework for Explaining Reactions to Decisions: Interactive Effects of Outcomes and Procedures. Psychological Bulletin 120 (2): 189-208. https://doi.org/10.1037/0033-2909.120.2.189.

Carpenter, Daniel. 2001. The Forging of Bureaucratic Autonomy: Reputations, Networks, and Policy Innovation in Executive Agencies, 1862-1928. Princeton, NJ: Princeton University Press.

Chanley, Virginia A., Thomas J. Rudolph, and Wendy M. Rahn. 2000. The Origins and Consequences of Public Trust in Government: A Time Series Analysis. The Public Opinion Quarterly 64 (3): 239-256. https://doi.org/10.1086/317987.

Citrin, Jack, and Donald Philip Green. 1986. Presidential Leadership and the Resurgence of Trust in Government. British Journal of Political Science 16 (4): 431-453. https://doi.org/10.1017/S00071234 00004518.

Citrin, Jack, and Laura Stoker. 2018. Political Trust in a Cynical Age. Annual Review of Political Science 21 (11): 49-70. https://doi.org/10.1146/annurevpolisci-050316-092550.

Colquitt, Jason A., Donald E. Conlon, Michael J. Wesson, Christopher OLH Porter, and K. Yee Ng. 2001. Justice at the Millennium: A Meta- Analytic Review of 25 Years of Organizational Justice Research. Journal of Applied Psychology 86 (3): 425. https://doi.org/10.1037/0021-9010.86.3.425.

Cooper, Christopher A., H. Gibbs Knotts, and Kathleen M. Brennan. 2008. The Importance of Trust in Government for Public Administration: The Case of Zoning. Public Administration Review 68 (3): 459-468. https://doi.org/10.1111/j.1540-6210.2008.00882.x.

Cuddy, Amy J. C., Susan T. Fiske, and Peter Glick. 2007. The BIAS Map: Behaviors from Intergroup Affect and Stereotypes. Journal of Personality and Social Psychology 92 (4): 631-648. https://doi.org/10.1037/ 0022-3514.92.4.631. 
Dalton, Russell J. 2004. Democratic Challenges, Democratic Choices: The Erosion of Political Support in Advanced Industrial Democracies [in English]. Oxford University Press.

Esaiasson, Peter, Mikael Persson, Mikael Gilljam, and Torun Lindholm. 2019. Reconsidering the Role of Procedures for Decision Acceptance. British Journal of Political Science 49 (1): 291-314. https://doi.org/ 10.1017/S0007123416000508.

Fiske, Susan T. 2018. Political Cognition Helps Explain Social Class Divides: Two Dimensions of Candidate Impressions, Group Stereotypes, and Meritocracy Beliefs. Cognition 188:108-115. https://doi.org/10. 1016/j.cognition.2018.11.007.

Fiske, Susan T., Amy J. C. Cuddy, and Peter Glick. 2007. Universal Dimensions of Social Cognition: Warmth and Competence. Trends in Cognitive Sciences 11 (2): 77-83. https://doi.org/10.1016/j.tics. 2006.11.005.

Fiske, Susan T., Amy J. C. Cuddy, Peter Glick, and Jun Xu. 2002. A Model of (Often Mixed) Stereotype Content: Competence and Warmth Respectively Follow from Perceived Status and Competition. Journal of Personality and Social Psychology 82 (6): 878-902. https://doi.org/10.1037/0022-3514.82.6.878.

Fiske, Susan T., Juan Xu, Amy C. Cuddy, and Peter Glick. 1999. (Dis) Respecting versus (Dis) Liking: Status and Interdependence Predict Ambivalent Stereotypes of Competence and Warmth. Journal of Social Issues 55 (3): 473-489. https://doi.org/10.1111/0022-4537.00128.

Goodwin, Geoffrey P., Jared Piazza, and Paul Rozin. 2014. Moral Character Predominates in Person Perception and Evaluation. Journal of Personality and Social Psychology (US) 106 (1): 148-168. https://doi.org/10.1037/a0034726.

Grimes, Marcia. 2006. Organizing Consent: The Role of Procedural Fairness in Political Trust and Compliance. European Journal of Political Research 45 (2): 285-315. https://doi.org/10.1111/j.14756765.2006.00299.x.

Grimmelikhuijsen, Stephan G., and Albert J. Meijer. 2014. Effects of Transparency on the Perceived Trustworthiness of a Government Organization: Evidence from an Online Experiment. Journal of Public Administration Research and Theory 24 (1): 137-157. https://doi.org/10.1093/jopart/mus048.

Halkias, Georgios, and Adamantios Diamantopoulos. 2020. Universal Dimensions of Individuals' Perception: Revisiting the Operationalization of Warmth and Competence with a Mixed-Method Approach. International Journal of Research in Marketing, https://doi.org/10.1016/j.ijresmar.2020.02.004.

Hansen, Frederik Godt. 2021. Replication Data for: Can Warm Behavior Mitigate the Negative Effect of Unfavorable Governmental Decisions on Citizens' Trust? https://doi.org/10.7910/DVN/KAMSQK.

Hetherington, Marc J. 1998. The Political Relevance of Political Trust. American Political Science Review 92 (4): 791-808. https://doi.org/doi:10.2307/2586304.

Hibbing, John R., and John R. Alford. 2004. Accepting Authoritative Decisions: Humans as Wary Cooperators. American Journal of Political Science 48 (1): 62-76. https://doi.org/10.2307/1519897.

Hibbing, John R., and Elizabeth Theiss-Morse. 2002. Stealth Democracy: Americans'Beliefs about How Government Should Work. Cambridge: Cambridge University Press.

Imai, Kosuke, Luke Keele, Dustin Tingley, and Teppei Yamamoto. 2011. Unpacking the Black Box of Causality: Learning about Causal Mechanisms from Experimental and Observational Studies. American Political Science Review 105 (4): 765-789. https://doi.org/doi:10.1017/S0003055411000414.

Imai, Kosuke, Dustin Tingley, and Luke Keele. 2010. A General Approach to Causal Mediation Analysis. Psychological Methods 15 (4): 309-334. https://doi.org/10.1037/a0020761.

Judd, Charles M., Laurie James-Hawkins, Vincent Yzerbyt, and Yoshihisa Kashima. 2005. Fundamental Dimensions of Social Judgment: Understanding the Relations between Judgments of Competence and Warmth. Journal of Personality and Social Psychology, 899-913. https://doi.org/10.1037/00223514.89.6.899.

Keele, Luke. 2007. Social Capital and the Dynamics of Trust in Government. American Journal of Political Science 51 (2): 241-254. https://doi.org/10.1111/j.1540-5907.2007.00248.x.

Kruglanski, Arie W., and Donna M. Webster. 1996. Motivated Closing of the Mind: "Seizing" and "Freezing." Psychological Review (US) 103 (2): 263-283. https://doi.org/10.1037/0033-295X.103.2.263.

Kunda, Ziva. 1990. The Case for Motivated Reasoning. Psychological Bulletin 108 (3): 480-498. https://doi. org/10.1037/0033-2909.108.3.480.

Laustsen, Lasse, and Alexander Bor. 2017. The Relative Weight of Character Traits in Political Candidate Evaluations: Warmth Is More Important than Competence, Leadership and Integrity. Electoral Studies 49:96-107. https://doi.org/10.1016/j.electstud.2017.08.001. 
Leach, Colin Wayne, Naomi Ellemers, and Manuela Barreto. 2007. Group Virtue: The Importance of Morality (vs. Competence and Sociability) in the Positive Evaluation of in-Groups. Journal of Personality and Social Psychology (US) 93 (2): 234-249. https://doi.org/10.1037/0022-3514.93.2.234.

Lee, Danbee, and Gregg G. Van Ryzin. 2020. Bureaucratic Reputation in the Eyes of Citizens: An Analysis of US Federal Agencies. International Review of Administrative Sciences, 86 (1): 183-200.

Lewis-Beck, Michael S., and Mary Stegmaier. 2013. The VP-Function Revisited: A Survey of the Literature on Vote and Popularity Functions after over 40 Years [in en]. Public Choice 157 (3-4): 367-385. https:// doi.org/10.1007/s11127-013-0086-6.

Lipsky, Michael. 1980. Street-Level Bureaucracy: Dilemmas of the Individual in Public Service. New York: Russell Sage Foundation.

Magalhaes, Pedro C., and Luis Aguiar-Conraria. 2019. Procedural Fairness, the Economy, and Support for Political Authorities [in English]. Political Psychology 40 (1): 165-181. https://doi.org/10.1111/pops. 12500.

Marien, Sofie, and Marc Hooghe. 2011. Does Political Trust Matter? An Empirical Investigation into the Relation between Political Trust and Support for Law Compliance. European Journal of Political Research 50 (2): 267-291. https://doi.org/10.1111/j.1475-6765.2010.01930.x.

Mayer, Roger C., James H. Davis, and F. David Schoorman. 1995. An Integrative Model of Organizational Trust. The Academy of Management Review 20 (3): 709-734. https://doi.org/10.2307/258792.

Maynard-Moody, Steven Williams, and Michael Musheno. 2003. Cops, Teachers, Counselors: Stories from the Front Lines of Public Service. Ann Arbor: University of Michigan Press.

Ministry of Health. 2017. Plejecentre. https://www.sum.dk/Aeldre/Boliger-tilaeldre/Plejecentre.aspx.

Nannestad, Peter, and Martin Paldam. 1994. The VP-Function: A Survey of the Literature on Vote and Popularity Functions after 25 Years. Public Choice 79 (3): 213-245. https://doi.org/10.1007/BF01047771.

OECD. 2017. Government at a Glance 2017. OECD Publishing.

Pedersen, Rasmus T. 2017. Politicians Appear More Competent When Using Numerical Rhetoric [in en]. Journal of Experimental Political Science 4 (2): 129-150. https://doi.org/10.1017/XPS.2017.7.

Perkins, David N. 1985. Postprimary Education Has Little Impact on Informal Reasoning. Journal of Educational Psychology 77 (5): 562-571. https://doi.org/10.1037/0022-0663.77.5.562.

Pop-Eleches, Cristian, and Grigore Pop-Eleches. 2012. Targeted Government Spending and Political Preferences [in en]. Quarterly Journal of Political Science 7 (3): 285-320. https://doi.org/10.1561/100. 00011017.

Popkin, Samuel L. 1991. The Reasoning Voter: Communication and Persuasion in Presidential Campaigns Chicago. London: University of Chicago Press.

Redlawsk, David P, Andrew JW Civettini, and Karen M Emmerson. 2010. The Affective Tipping Point: Do Motivated Reasoners Ever "Get It"? Political Psychology 31 (4): 563-593. https://doi.org/10.1111/j. 1467-9221.2010.00772.x.

Scholz, John T., and Mark Lubell. 1998. Trust and Taxpaying: Testing the Heuristic Approach to Collective Action. American Journal of Political Science 42 (2): 398-417. https://doi.org/10.2307/2991764.

Stanovich, Keith E., and Richard F. West. 2007. Natural Myside Bias Is Independent of Cognitive Ability. Thinking \& Reasoning 13 (3): 225-247. https://doi.org/10.1080/13546780600780796.

Stanovich, Keith E., Richard F. West, and Maggie E. Toplak. 2013. Myside Bias, Rational Thinking, and Intelligence. Current Directions in Psychological Science 22 (4): 259-264. https://doi.org/10.1177/ 0963721413480174.

Statistics Denmark. 2020a. NYT: Flest kvinder bor p_a plejehjem eller i pleje- bolig [in da]. https://www.dst. $\mathrm{dk} / \mathrm{da} /$ Statistik/nyt/NytHtml?cid=30746.

Statistics Denmark. 2020b. NYT: Fortsat f_rre_ldre bor i pleje- og_ldreboliger [in da]. https://www.dst.dk/ $\mathrm{da} /$ Statistik/nyt/NytHtml?cid=32187.

Thomsen, Mette Kjaergaard, and Ulrich Thy Jensen. 2020. Service Professionals' Response to Volunteer Involvement in Service Production. Journal of Public Administration Research and Theory 30 (2): 220-239. https://doi.org/10.1093/jopart/muz028.

Tingley, Dustin, Teppei Yamamoto, Kentaro Hirose, Luke Keele, and Kosuke Imai. 2014. Mediation: R Package for Causal Mediation Analysis. Journal of Statistical Software 59 (1): 1-38. https://doi.org/10. 18637/jss.v059.i05.

Tyler, Tom R. 1990. Why People Obey the Law. Princeton: Princeton University Press. 
Van Erkel, Patrick F.A., and Tom W.G. Van der Meer. 2016. Macroeconomic Performance, Political Trust and the Great Recession: A Multilevel Analysis of the Effects of within-Country Fluctuations in Macroeconomic Performance on Political Trust in 15 EU Countries, 1999-2011. European Journal of Political Research 55 (1): 177-197. https://doi.org/10.1111/14756765.12115.

Van Ryzin, Gregg G. 2011. Outcomes, Process, and Trust of Civil Servants. Journal of Public Administration Research and Theory 21 (4): 745-760. https://doi.org/10.1093/jopart/muq092.

Wojciszke, Bogdan, Roza Bazinska, and Marcin Jaworski. 1998. On the Dominance of Moral Categories in Impression Formation. Personality and Social Psychology Bulletin 24 (12): 1251-1263. https://doi.org/ 10.1177/01461672982412001.

Wolfe, Christopher R., M. Anne Britt, and Jodie A. Butler. 2009. Argumentation Schema and the Myside Bias in Written Argumentation. Written Communication 26 (2): 183-209. https://doi.org/10.1177/07410 88309333019 .

Cite this article: Hansen FG (2023). Can Warm Behavior Mitigate the Negative Effect of Unfavorable Governmental Decisions on Citizens' Trust? Journal of Experimental Political Science 10, 62-75. https:// doi.org/10.1017/XPS.2021.23 